\title{
Development, adaptation and application of a rehabilitation technology - art-based assessments of art therapy: An overview of the current situation in Latvia
}

\author{
Elza Strazdina \\ Rīga Stradiņš University, Latvia \\ Latvian Art Therapy association, Latvia
}

\begin{abstract}
The aim of this study is to give an overview on the current situation of art-based assessment in Latvia, focusing on the adaptation and its results of The Bridge Drawing (TBD) assessment tool. The study consisted of two stages - the adaptation of TBD in Latvian and examination of its content validity and psychometric data; the use of adapted instrument in order to investigate any differences in TBD drawings between clients with symptomatic eating disorders and those without. In the first stage of the study, 40 respondents participated, while in the second stage 50 participants (25 respondents with symptomatic eating disorders and 25 without such diagnosis) were selected. It was concluded that the psychometric data generally shows adequate results in most of the quantitative TBD scales. Statistically significant correlation between a number of TBD and COPE-LV scales was detected, suggesting that TBD can be used to determine problemsolving strategies. This research also revealed various differences in TBD drawings of clients with symptomatic eating disorders.
\end{abstract}

Key words: art therapy, art-based assessment, assessment tools, test adaptation, The Bridge Drawing.

\section{Introduction}

Since the turn of the 20th century, various professionals (including doctors, psychiatrists, psychologists, teachers, etc.) have acknowledged the important role of art in the process of treatment. For over a century various visual methods, such as projective drawings and tests, have been used as a tool to gain deeper understanding of the human psyche [1-3]. From these visual methods, art-based assessment in art therapy emerged. Assessment in art therapy consists of the use of any combination of verbal, written, and art tasks, which are chosen by a professional art therapist in order to assess individual's level of functioning, problem areas, strengths, and treatment objectives [4, 5]. This assessment is done using several tools both subjective and objective such as an interview, observation, tests, questionnaires, as well as art-based assessment tools. PhD, art therapist Donna Betts indicates that art-based assessment tools are standardized measures designed by an art therapist and incorporate various drawing materials, such as markers, coloured pencils [5]. The ability to select and use aforementioned instruments is one of the basic competences of art therapist working in any setting worldwide [5, 7-9]. 
Such standardized assessments are fundamental to all disciplines that deal with intervention, indicating its important role to rehabilitation setting and treatment. Many art therapy practitioners believe that assessments bring deeper understanding of a client's emotional, cognitive, physiological and social functioning $[5,10,11]$. The artwork of a client can reveal his or her everyday reality - one's family, work, thoughts and feelings about oneself, values of life, and cultural roles, which can bring beneficial information to the whole rehabilitation team in setting treatment goals, coordinating treatment plan, and evaluating treatment results. For those suffering from impaired verbal abilities, it can provide an alternative and different means of communication [12].

Currently there are 27 art-based assessment tools known to art therapists worldwide [5], but only 6 such instruments (The Formal Elements Art Therapy Scale, FEATS, Gantt, Tabone, 1998; Birds Nest Drawing, Kaiser, 1993; Diagnostic Drawing Series, Cohen, Hammer, Singer, 1988; Draw a Story; Silver, 1988, 1993, 2002; Silver Drawing Test of cognition and emotion, Silver, 1975/2002, The Bridge Drawing, Heys \& Lyons, 1981) are adapted for use in Latvia, while several of the instruments are still in the process of adaptation.

Although there are many benefits from the use of such art-based assessment instruments in art therapy, there are notions about their drawbacks. The need for evidence-based art therapy practice [13-16] has highlighted the insufficiency of data regarding the validity and reliability, as well as applicability of such instruments in variety of different client/patient groups. Therefore, the research goal of this study was to adapt TBD in Latvia, to assess its correlation with problem solving strategies and to determine whether any differences exist between the drawings of two study groups. The tasks of this study were: 1) to undergo the adaptation of TBD in Latvia and to assess its psychometric data; 2) to determine the correlation between TBD Rating scales and COPE-LV inventory scales; 3) to identify and characterize differences in TBD drawings of clients suffering from symptomatic eating disorders and those without; and 4) to investigate what kind of content characteristics of TBD are found in the drawings of clients suffering from symptomatic eating disorders.

\subsection{The Bridge Drawing}

The Bridge Drawing (TBD) [17] is an art based assessment tool developed in 1981 by American art therapists Ronald Hays and Sherry Lyons. Grounding their idea in the symbolic meaning of the bridge, the authors of the instrument considered it as a way of overcoming obstacles and seeking new ways of coping with problems, indicating individuals' resources, emerging issues and their ability to overcome them [17-20].

Originally authors distinguished 12 TBD rating criteria partially based on the work of American psychologist Emanuel Hammer [17]: (1) directionality, (2) placement of self in picture, (3) places drawn on either side of bridge, (4) solidarity of bridge attachments, (5) emphasis by elaboration, (6) bridge construction, (7) type of bridge depicted, (8) matter down under the bridge (9) vantage point of the viewer, (10) axis of the paper, (11) consistency of gestalt, and (12) written associations to drawings. In 2012 American art therapists Katrin Martin and Donna Betts created new rating manual (The Bridge Drawing rating manual [21] ) with 24 rating scales, which consisted of 12 rating criteria developed by Hays and Lyons, as well as incorporated rating scales from The Formal Elements Art Therapy scale [22]: Prominence of Color, Color Fit, Energy Expended, Space, Integration, Logic, Realism, Developmental Level, Details in Bridge \& Environment, Solidarity of Bridge Attachments to Ground, Bridge Construction, Presence of Threat, Matter Under the Bridge, Presence of Hope, Word Inclusion, Problem Solving, Line Quality, Placement of Figure/Dot in the Picture, Direction of the Arrow, Emphasis by Elaboration, Vantage Point of the Viewer, Places Drawn on Either Side of the Bridge, Type of Bridge Depicted, Axis of the Paper. 
TBD has been used for various purposes - to determine the problem solving strategies of a client/patient, to represent the past experience and future expectations [17-20], as well as emotional state of a client. It has been used also with various populations - children who suffer from oncologic diseases[19], adolescents [23], orphans [24], patients with mental problems [20], university students [25], immigrants [26], incarcerated women [27].

\subsection{The present study}

Due to the lack of variety of art-based assessment tools in Latvia and the lack of research of the validity and responsibility of art-based assessment tools, the purpose of this study was to adapt an art-based assessment tool The Bridge Drawing [17] in Latvia, to ascertain its relation to problem-solving, and to determine whether and what differences are observed in TBD drawings in various client / patient groups. The research was conducted as a part of Master degree thesis in collaboration with art therapist Margarita Stolyarova [28].

\section{Material and methods}

\subsection{Participants}

In the first stage of the study 40 respondents $(n=40)$ participated among who were both males and females at the age of 18 to 65 . Respondents had no record of previous mental illness or severe physical injuries. One of the principal exclusion criteria in this study was a previous art experience (education in art, art classes, etc.).

In the second stage, 50 women participated of the age 18-65, 25 of whom had shown signs of symptomatic eating disorders and 25 without such tendencies. The participants of the clinical group were selected in collaboration with nutritionist and health care professional Inga Puce and by using The Eating Attitudes Test (EAT-26) [29] as a screening measure.

\subsection{Methods}

The Bridge Drawing (TBD) - was adapted for the use of this study by art therapists Strazdina and Stollarova [28]. Each participant was provided with a $297 \times 420 \mathrm{~mm}$ sheet of white drawing paper and a box with 24 colour Faber-Castell pencils. Participants were asked to "Draw a bridge going from one place to another. Point out your location. Using an arrow show the direction of movement". There were no time constraints in completing the task.

Eating Attitudes Test EAT-26. The Latvian version of EAT-26 was used, which is a standardized self-report measure of symptoms and concerns characteristic of eating disorders [29].

The Coping Orientation of Problem Experience Inventory (COPE-LV). To ascertain TBD correlation with problem-solving strategies the Latvian version of COPE was used. $\mathrm{COPE}$ is a self-report questionnaire, consisting of 60 questions, designed to explore various coping behaviours of individuals. The inventory consists of 15 scales: Active coping, Planning, Suppression of competing activities, Restraint coping, Seeking social support for instrumental reasons, Seeking social support for emotional reasons, Positive reinterpretation \& growth, Acceptance, Turning to religion, Focus on \& venting of emotions, Denial, Behavioural disengagement, Mental disengagement, Alcohol-drug disengagement [30]. 


\subsection{Procedure}

The study consisted of two stages. In the 1st stage the adaptation of TBD in Latvian was conducted and the validity of its translated versions' psychometric data and content was delaminated.

In the 2nd stage the assessment was used in order to determine differences between drawings of patients with symptomatic eating disorders, patients suffering from depression, and those without such tendencies (in this article the results of TBD of patients with symptomatic eating disorders will be discussed).

\section{Results}

The processing of data was done by using SPSS 20 (Statistical Package for the Social Sciences). Both descriptive and inferential statistics were used for data analysis. Statistical analysis was conducted only for the first 15 Likert-type rating scales.

Results show adequate item difficulty indices in 10 TBD scales $(M=[1.4-2.6])$, except Scales 4 and 6 which show heightened results, and scales 12 and 13 which show lowered results (scale 12: $M=1.17, \mathrm{SD}=0.38$; scale $13: M=1.13, \mathrm{SD}=0.35$ ).

To ascertain correlation between three independent expert ratings of TBD, Intraclass Correlation Coefficient (ICC) was used. The results show high (ICC $\geq 0.8$ ) correlation between the independent expert ratings in 13 TBD scales.

As mentioned before, in order to ascertain TBD correlation with problem-solving strategies of COPE-LV Spearman's rank correlation coefficient $\left(r_{s}\right)$ was used (see Fig. 1). In this study, it was found that in a number of scales, there is a relationship between TBD and problem-solving strategies. As shown in Fig. 1, statistically significant strong positive $(r \geq 0.37)$ and negative $(r \geq-0.39)$ correlation $(p<0.05, p<0.01)$ between nine COPE-LV scales and individual TBD scales, such as Prominence of Colour, Energy Expanded, Space, Integration, Logic, Details in Bridge \& Environment, Solidarity of Bridge Attachments to Ground, Bridge Construction, Matter Under the Bridge and Presence of hope, can be detected. The results show also several trends where the Spearman correlation coefficient is relatively high (0.3 to 0.35$)$, but the calculations do not show statistical significance $(p<0.05, p<0.01)$, which should be tested in future studies.

In order to determine if any differences between TBD drawings of people with and without symptomatic eating disorders can be detected, Mann-Whitney U test (U) was used. As results show, statistically significant differences in TBD of clients with symptomatic eating disorders in scales Energy Expended $(Z=-1.97, p=0.05)$, Logic $(Z=-2.04$, $p=0.04)$, Solidarity of Bridge Attachments to Ground $(Z=-2.43, p=0.01)$, Bridge Construction $(Z=-3.11, p=0.00)$, and Matter Under the Bridge $(Z=-2.03, p=0.04)$ can be detected (Fig. 2).

Content analysis of the elements of TBD drawings for both groups was also done. It was determined that clients with symptomatic eating disorders tend either to more often depict an impossible solution (or crossing of an obstacle) (28\%) or draw no bridge at all (12\%). Mostly controlled lines are used $(80 \%)$, there is no indication of places on either side of the bridge $(60 \%)$, or they are drawn miniscule. Usually a wooden arch bridge is drawn, which was relevant to both client groups. Some of the patients with symptomatic eating disorders tend to romanticize the bridge or draw it in an abstract way (e.g., three hearts intertwined).

\section{Discussion}

This study was designed to show the results of adaptation and application of art-based assessment tool The Bridge drawing in Latvia in various settings. 


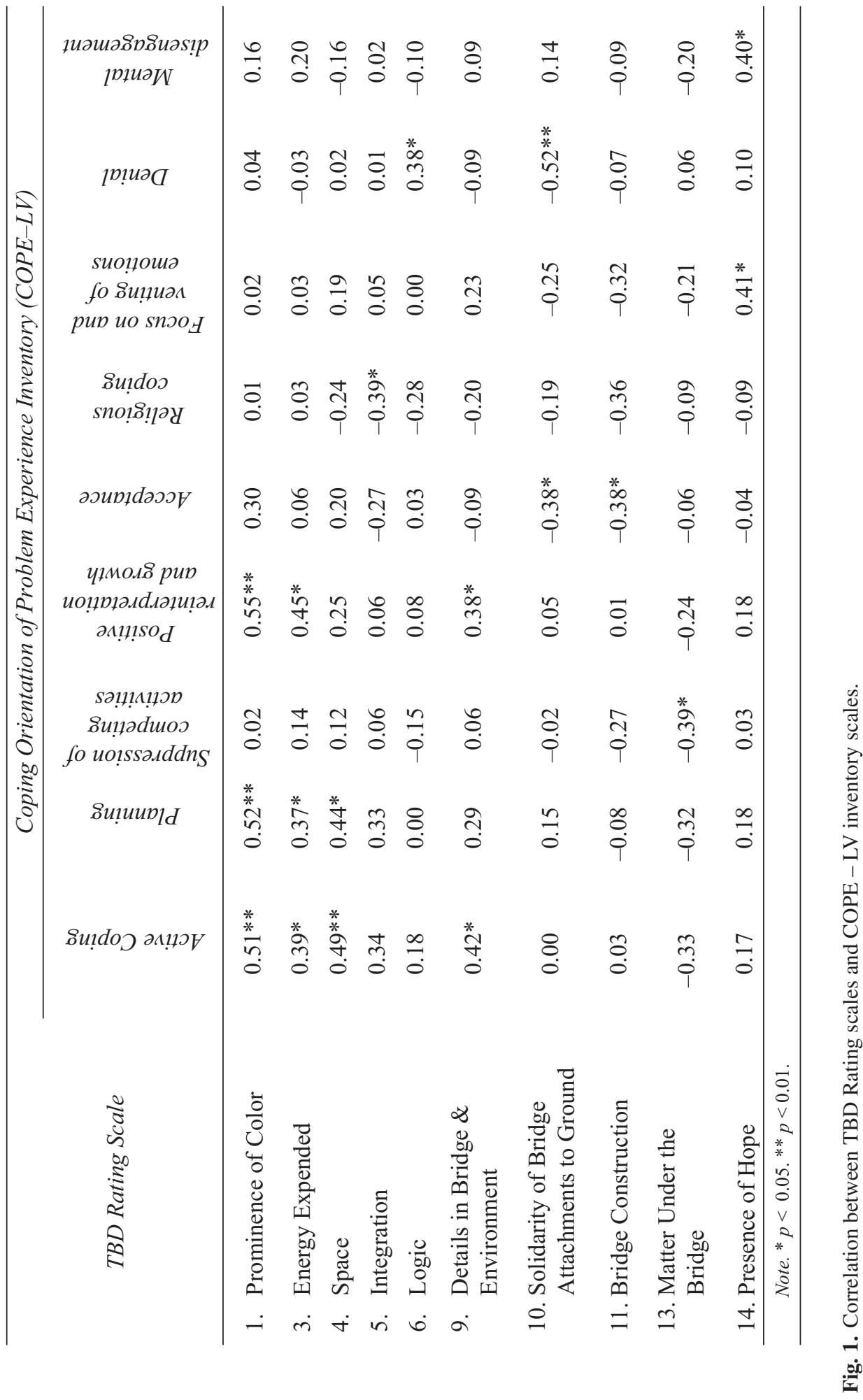




\begin{tabular}{|c|c|c|c|c|c|c|}
\hline \multirow[t]{2}{*}{ TBD rating scale } & \multicolumn{2}{|c|}{$\begin{array}{c}\text { Clinical group } \\
(n=25)\end{array}$} & \multicolumn{2}{|c|}{$\begin{array}{c}\text { Control group } \\
(n=25)\end{array}$} & \multirow[t]{2}{*}{$Z$} & \multirow[t]{2}{*}{$p$} \\
\hline & $M$ & $S D$ & $M$ & $S D$ & & \\
\hline 3. Energy Expended & 1.76 & 0.52 & 2.04 & 0.45 & -1.97 & 0.05 \\
\hline 6. Logic & 2.69 & 0.63 & 2.96 & 0.20 & -2.04 & 0.04 \\
\hline $\begin{array}{l}\text { 10. Solidarity of } \\
\text { Bridge } \\
\text { Attachments to } \\
\text { Ground }\end{array}$ & 1.76 & 0.83 & 2.32 & 0.69 & -2.43 & 0.01 \\
\hline $\begin{array}{l}\text { 11. Bridge } \\
\text { Construction }\end{array}$ & 1.68 & 0.69 & 2.28 & 0.54 & -3.11 & 0.00 \\
\hline $\begin{array}{l}\text { 13. Matter Under the } \\
\text { Bridge }\end{array}$ & 1.28 & 0.54 & 1.04 & 0.20 & -2.03 & 0.04 \\
\hline
\end{tabular}

Note. $p \leq 0.05$.

Fig. 2. Differences of TBD rating scale results for clinical and control group.

The results of this research show that the overall psychometric data generally shows high item difficulty indices in most of the TBD scales that are measured quantitatively, as well as high inter-rater correlation in 13 quantitative TBD scales. It should be noted that the sample of this research was relatively small and there is no pre-existing research on TBD item difficulty indices, therefore comparison with other data is impossible. This requires future research both with TBD or other art-based assessment tools with larger samples and with various client/patient groups. Some authors [31] indicate that more specific and defined descriptions for each rating scale should be developed in order to eliminate subjective rating thus affecting the validity of results.

The results also show correlation between various specific TBD and COPE LV scales indicating that TBD partially measures and reveals clients' problem-solving strategies. Nevertheless, for the utmost credibility of data this should be tested in larger samples.

It was concluded that there are statistically significant differences in TBD between clients with and without symptomatic eating disorders in scales Energy Expended, Logic, Solidarity of Bridge Attachments to Ground, Bridge Construction and Matter Under the Bridge. Based on the description of these scales, they can be associated with psycho-emotional and functioning difficulties of people suffering from symptomatic eating disorders symptoms such as fatigue, decreased energy, distorted perception of themselves and their appearance, difficulty in dealing with complex life situations $[32,33]$. This too can be extended to the content characteristics of TBD drawings. It should also be noted that although the clinical group was selected in collaboration with a health care professional, the symptomatic eating disorders in this study cannot be perceived as a diagnosis.

\section{Conclusions}

Overall, the present study shows that TBD can be used as an art-based assessment tool in Latvia and it partially measures problem-solving tendencies. Although this study shows promising data, research on the validity and reliability of TBD and other instruments adapted 
in Latvia and those used worldwide should be continued in larger samples and with various client/patient groups.

It should be ensured that art therapists receive training in the use of assessment rating manuals. In addition, future adaptation and creation of art-based assessments in Latvia should be promoted.

\section{References}

[1] G.D. Oster, P. Gould Crone, Using drawings in assessment and therapy: A guide for mental health professionals (Brunnder-Routledge, New York, NY, 2004)

[2] J.M. MacGregor, The discovery of the art of the insane (Princeton University Press, Princeton, NJ, 1989)

[3] C.A. Malchiodi, Understanding children's drawings (Guilford Press, New York, 1998)

[4] American Art Therapy Association (2004) Education standards. Retrieved. http:// www . art therapy . org/aboutaata/educationstandards.pdf

[5] Nacionālais veselības dienests (NVD). Izvērsts medicīniskās tehnologijas "mākslas terapija" apraksts. Iegūts no: Nacionālais veselības dienests: http://www . vmnvd.gov. Iv (2010)

[6] D.J. Betts, A systematic analysis of art therapy assessment and rating instrument literature Doctoral dissertation (Florida State University, Tallahassee, 2005)

[7] Health \& care professions council. Standards of proficiency - Arts therapists (2013)

[8] Ethical Principles for Art Therapists. American Art Therapy Association (2013) Retrieved: http://www . americanarttherapyassociation.org/upload/ ethicalprinciples.pdf

[9] Latvijas Mākslas terapeitu ētikas kodekss (2010). Latvijas Mākslu terapijas asociācijuapvienība (LMTAA). Retrieved: http://www . arttherapy.1v/lv/lmta/ etikas-kodekss-slashkomisija

[10] J.A. Rubin, Art therapy: An introduction (Brunner/Mazel, Philadelphia, PA, 1999)

[11] L. Gantt, Art Ther. J. Am. Art Ther. Assoc. 21(1), 18-29 (2004)

[12] C. Malchiodi, Medical Art Therapy With Adults (Jessica Kingsley Publishers, London, Philadelphia, 1999)

[13] A. Gilroy, Art Therapy, Research and Evidence-based Practice (SAGE, 2006)

[14] A. Gilroy, R. Tipple, C. Brown, Assessment in Art Therapy (Routledge: New York, 2012), p. 227

[15] D.J. Betts, Positive art therapy assessment: Looking towards positive psychology for new directions in the art therapy evaluation process, edited by G.A. Tipple \& C. Brown Assessment in art therapy (Routledge, New York, NY, 2012), p. 203-218

[16] K. Mārtinsone, No Mākslas terapija: Teorija un prakse (Rīga: Drukātava, 2009), pp. 261-286

[17] R.E. Hays, S.J. Lyons, S.J. The Arts in Psychotherapy, pp. 207-217 (1981)

[18] S. Stepney, Art therapy with students at risk: Introducing art therapy into an alternative learning environment for adolescents (Charles C Thomas: Springfield, I.L., 2001)

[19] T. Councill, Med. Art Therapy with Children. In: Malchiodi, C. Handbook of art therapy (Guilford Press, New York, 2003), pp. 207-219

[20] T. Teneycke, J. Hoshino, D. Sharpe, The Arts in Psychotherapy (2009), pp. 297-303

[21] K. Martin, D. Betts, The Bridge Drawing Rating Manual (2nd ed.) Department of Art Therapy (George Washington University, Washington, DC, 2012)

[22] L. Gantt, C. Tabone, The Formal Elements Art Therapy Scale: The Rating Manual (Gargoyle Press, Morgantown, WV, 1998) 
[23] T. Yedidia, H. Itzhaky, Social work practice with children and families, edited by N.B. Webb, Mass trauma and violence (Guildford Press, New York, NY, USA, 2004), pp. 283-303

[24] O. Darewych, The Arts in Psychotherapy 40, 85-93 (2013)

[25] O.H. Darewych, The Bridge Drawing with Path Art-Based Assessment: Measuring Meaningful Life Pathways in Higher Education Students. A dissertation (lesley university, 2014)

[26] T. Yedidia, Clin. Soc. Work J. 33(2), 159-171 (2005)

[27] G.G. Ferszt, P.M. Hayes, S. DeFedele, L. Horn, J. Am. Art Ther. Assoc. 21(4), 191-199 (2004)

[28] E. Strazdina, M. Stoļarova, K. Mārtinsone, Uz mākslu balstītā izvēertēšanas instrumenta "Tilta zìmējums" adaptācija Latvijā. RSU konferences tēzes. (Rīga: RSU, 2016)

[29] D.M. Garner, M.P. Olmsted, Y. Bohr, P.E. Garfinkel, Psychological Med. 12, 871-878 (1982) Retrieved: http://www . eat-26.com/Docs/Garner-EAT-26-1982.pdf

[30] C.S. Carver, M.F. Scheier, \& J.K. Weintraub, J. Personality and S. Psychol. 56(2), 267-283 (1989)

[31] K.L. Scardino, A comparison of the bridge drawing projective test with women diagnosed with an eating disorder and women without the diagnosis of an eating disorder: A pilot study. Unpublished master's thesis (Hahnemann University, Philadelphia, PA, 1994)

[32] C.G. Fairburn, K. Bohn, Behav. Res. Ther. 43(6), 691-701 (2005)

[33] F.D. Garcia, H. Délavenne, P. Déchelotte, Nutr. Dietary Supplements 3, 67-75 (2011) 